\title{
Simulation of Telemetry System for Monitoring Fuel Level Based on SMS Gateway
}

\section{Simulasi Sistem Telemetri Pemantauan Level Ketinggian BBM Berbasis SMS Gateway}

\author{
Yuda Indra Pranata ${ }^{1}$, Muchlas ${ }^{2}$ \\ ${ }^{1}$ Mahasiswa Program Studi Teknik Elektro, Universitas Ahmad Dahlan, Indonesia \\ ${ }^{2}$ Dosen Program Studi Teknik Elektro, Universitas Ahmad Dahlan, Indonesia
}

\section{INFORMASI ARTIKEL}

\section{Riwayat Artikel:}

Dikirimkan 22 Januari 2020,

Direvisi 26 April 2020,

Diterima 14 Mei 2020.

\section{Kata Kunci:}

Level Ketinggian BBM, Sensor Ultrasonik HC-SR04, SIM800L,

SMS Gateway,

Mikrokontroler Arduino Uno.

\section{Penulis Korespondensi:}

Yuda Indra Pranata, Muchlas Program Studi Teknik Elektro, Universitas Ahmad Dahlan, Kampus 4 UAD, Jln Ring Road Selatan, Tamanan, Bangutapan, D.I.Yogyakarta, Indonesia.

Surel:

yudaindrapranata@gmail.com, muchlas@ee.uad.ac.id

\begin{abstract}
ABSTRAK
This study aims to simulate a telemetry system monitoring the level of the fuel level at an SMS-based gas station using an ultrasonic sensor integrated with the Arduino Uno microcontroller. The gas station's fuel tank was simulated using a 5 liter reservoir, while the HC-SR04 ultrasonic sensor was used to detect fuel level. The SIM800L module is used as a sender of information messages about the fuel level at a predetermined condition. This system is equipped with an LCD as a viewer when the data level is read. Based on testing the developed system can function well, shown by the average length of time the process of sending messages from reading the level limit on the tank, until the receipt of messages on mobile phones of 7.6 seconds. While the success rate of reading to the level of fuel level and sending automatic messages on the system reaches $100 \%$.
\end{abstract}

Penelitian ini bertujuan untuk membuat simulasi sistem telemetri pemantauan level ketinggian BBM di SPBU berbasis SMS gateway menggunakan sensor ultrasonik yang diintegrasikan dengan mikrokontroler Arduino Uno. Tangki BBM SPBU disimulasikan menggunakan sebuah tandon berkapasitas 5 liter, sedangkan sensor ultrasonik HC-SR04 digunakan untuk mendeteksi level ketinggian BBM. Modul SIM800L digunakan sebagai pengirim pesan informasi mengenai level ketinggian BBM pada kondisi yang telah ditentukan. Sistem ini dilengkapi dengan LCD sebagai penampil ketika data level terbaca. Berdasarkan pengujian sistem yang dikembangkan dapat berfungsi dengan baik, ditunjukkan oleh rata-rata lamanya waktu proses pengiriman pesan dari pembacaan level limit on tank, hingga diterimanya pesan pada handphone sebesar 7,6 detik. Sedangkan tingkat keberhasilan pembacaan terhadap level ketinggian BBM dan pengiriman pesan otomatis pada sistem tersebut mencapai $100 \%$.

This work is licensed under a Creative Commons Attribution-Share Alike 4.0

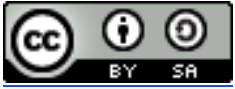

\section{Sitasi Dokumen ini:}

Y. I. Pranata and Muchlas, "Simulation of Telemetry System for Monitoring Fuel Level Based on SMS Gateway," Buletin Ilmiah Sarjana Teknik Elektro, vol. 2, no. 1, pp. 33-39, 2020. DOI: $\underline{10.12928 / \text { biste.v2i1.1604 }}$ 


\section{PENDAHULUAN}

Seiring dengan meningkatnya jumlah kendaraan bermotor, permintaan bahan bakar minyak (BBM) meningkat sehingga jumlah SPBU (stasiun pengisian bahan bakar umum) juga meningkat [1]. Setiap SPBU pada umumnya menjual bahan bakar sejenis pertamax, premium, solar dan pertamax plus [2]. SPBU memiliki tempat penyimpanan BBM berupa tangki atau bak penampung [3]. Proses pengukuran isi tangki BBM merupakan salah satu aktivitas penting dalam usaha SPBU, untuk mempermudah pengelolaan dan menunjang terciptanya kinerja yang efektif dan efisien [4]. Perusahaan memerlukan perangkat keras (hardware) dan juga perangkat lunak (software) yang dapat menangani langsung dalam proses pengolahan data tersebut [5].

Pada pengukuran isi tangki BBM SPBU, saat ini memang sudah tersedia metode pengukuran secara otomatis dengan menggunakan sensor level ketinggian BBM yang ditempatkan pada setiap tangki kemudian datanya dikirim dan ditampilkan melalui komputer di lokasi SPBU, namun sistem tidak dapat memenuhi kebutuhan pemantauan dari jarak jauh oleh pihak manajemen [6].

Sistem monitoring tangki pendam banyak digunakan pada SPBU, terutama digunakan untuk mengetahui stok BBM yang tersisa sehingga memudahkan SPBU untuk mengetahui kapan waktu yang tepat untuk memesan BBM kembali [7].

Seiring dengan perkembangan teknologi, saat ini telah tersedia teknologi SMS (Short Messege Service) [8]. Perangkat ini merupakan sebuah sistem yang digunakan untuk mengirim atau menerima SMS dan biasanya digunakan pada aplikasi bisnis baik untuk kepentingan broadcast promosi maupun informasi terhadap pengguna [9]. Melalui penelitian ini akan dikembangkan sistem monitoring telemetri level ketinggian BBM di SPBU dengan menggunakan aplikasi SMS Gateway berbasis mikrokontroler Arduino.

\section{METODE PENELITIAN}

\subsection{Perancangan Sistem Telemetri}

Blok diagram sistem telemetri pada sistem yang dikembangkan ditunjukkan pada Gambar 1. Berdasarkan blok diagram pada Gambar 1 pertama kali yang dilakukan oleh sistem tersebut adalah mendapatkan data dari sensor ultrasonik HC-SR04 dan di proses, sehingga ketika data yang diterima mencapai waktu yang telah ditentukan maka mikrokontroler Arduino Uno mengirimkan sinyal perintah kepada modul SMS gateway SIM800L untuk mengirim pesan ke nomor handphone yang telah terprogram, kemudian handphone penerima akan menerima pesan dari modul sistem tersebut [10].

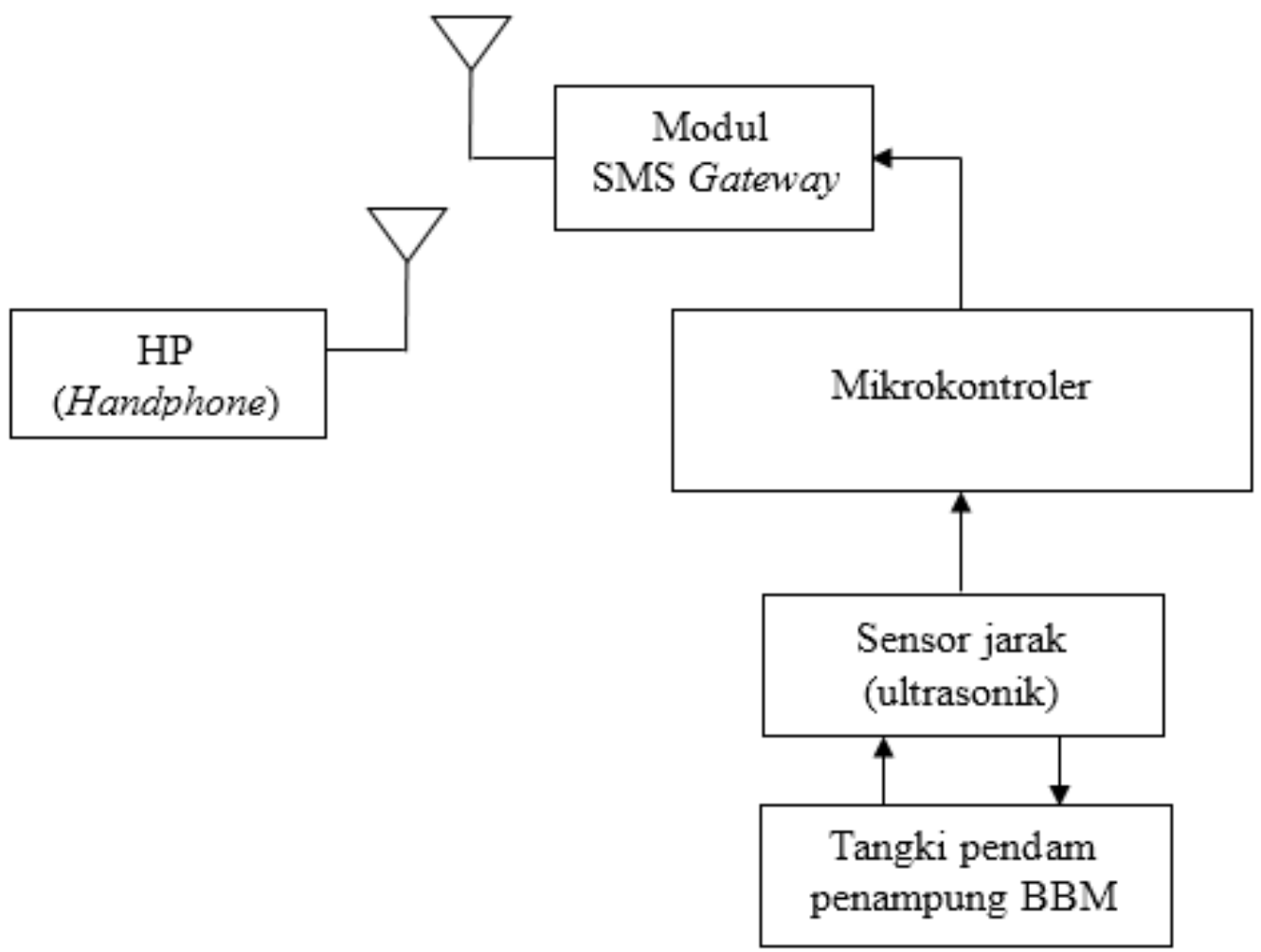

Gambar 1. Diagram Blok Sistem Telemetri 


\subsection{Perancangan Sistem software}

Perancangan sistem software pada simulasi sistem telemetri pemantauan level ketinggian BBM di SPBU berbasis SMS gateway dipresentasikan dalam bentuk diagram alir. Diagram alir inilah yang akan membantu dalam pembuatan program pada perancangan sistem software. Berikut gambar diagram alir dari program tampilan data ketinggian level BBM pada LCD.

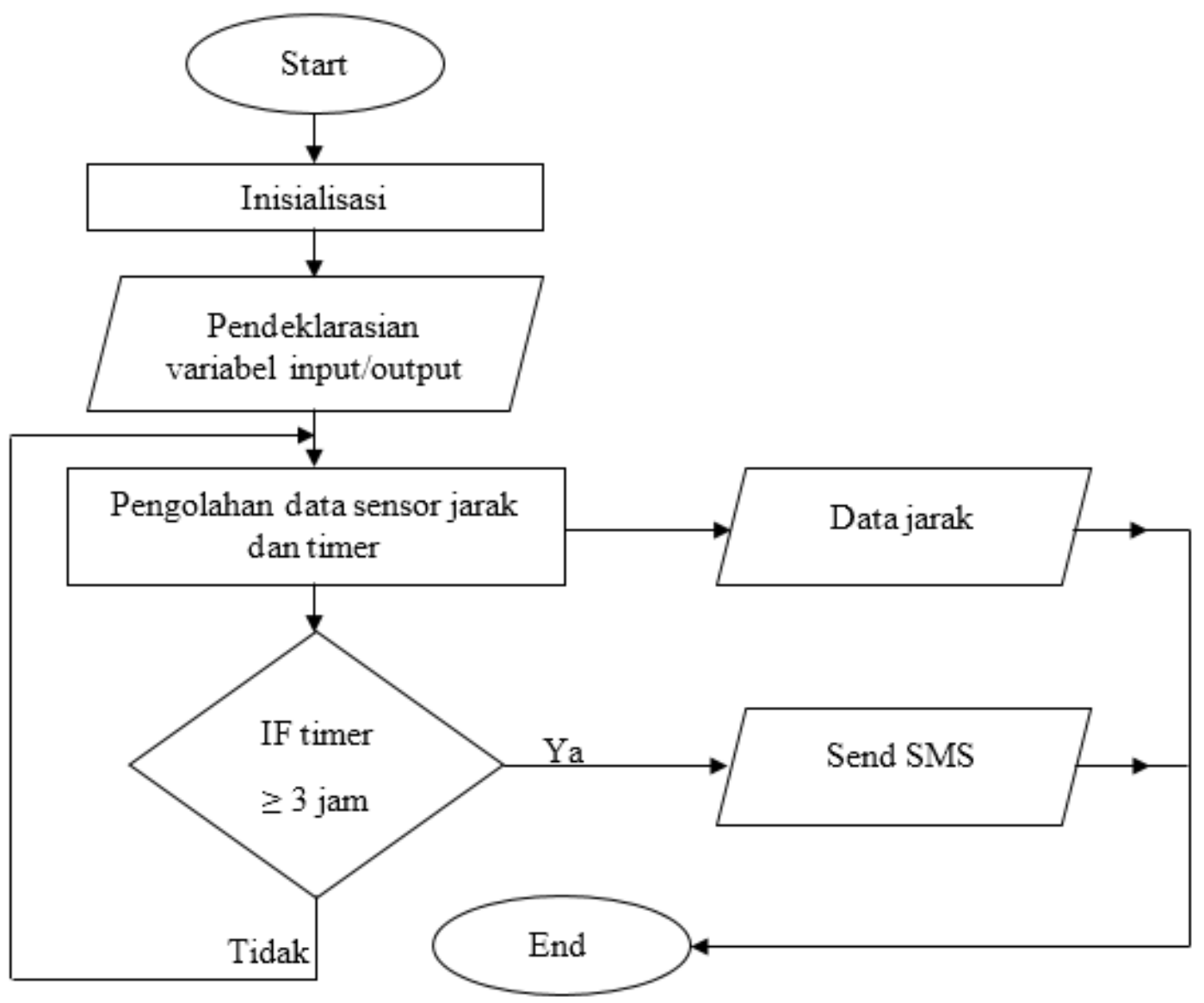

Gambar 2. Diagram Alir Program Tampilan Data Ketinggian Level Pada LCD

Program data ketinggian level BBM tersebut terbagi menjadi 3 bagian yaitu level full, level medium dan level limit. Level full adalah data ketika BBM dalam kondisi batas maksimum, level medium adalah data ketika BBM dalam kondisi batas tengah. Sedangkan level limit adalah data ketika BBM dalam kondisi batas minimum. Keadaan batas maksimum yang digunakan dalam penelitian ini adalah ketika jarak sensor terhadap BBM pada jarak $\mathrm{x}<=9 \mathrm{~cm}$, dan keadaan batas tengah adalah ketika jarak sensor terhadap BBM berada pada $\mathrm{x}>=10 \mathrm{~cm}$ sampai $19 \mathrm{~cm}$, serta keadaan batas minimum ketika jarak sensor terhadap BBM pada jarak $\mathrm{x}>=20 \mathrm{~cm}$. Setelah memasukkan data level ketinggian BBM, kemudian program melakukan pemilihan data dan waktu yang telah ditentukan selama 3 jam untuk mengirim data otomatis. Jika nilai data level ketinggian BBM pada jarak $\mathrm{x}<=9 \mathrm{~cm}$, maka sistem akan menampilkan hasil baca data full on tank. Jika jarak data level ketinggian BBM $x>=10 \mathrm{~cm}$ sampai $19 \mathrm{~cm}$, maka sistem akan menampilkan hasil baca data medium on tank. Jika jarak data level ketinggian $>=20 \mathrm{~cm}$, maka sistem akan menampilkan hasil baca data limit on tank. Kemudian program akan kembali ke awal yaitu inisialisasi program untuk melakukan proses ulang penampilan data level ketinggian BBM.

\section{HASIL DAN PEMBAHASAN}

Melalui penelitian ini dilakukan berbagai macam pengujian baik dalam sistem rangkaian, kinerja sensor, hingga pengujian sistem secara terpadu. Pengujian ini dilakukan untuk memastikan semua unit sistem sudah berjalan dan berfungsi dengan baik. 


\subsection{Pengujian Sensor Ultrasonik HC-SR04}

Pengujian ini dilakukan untuk mengetahui kemampuan sensor ultrasonik HC-SR04 dalam mendeteksi jarak antara benda dengan sensor tersebut. Pengukuran jarak pada sensor dilakukan dengan meletakkan sebuah benda di depannya dengan jarak tertentu dan nilainya dapat dilihat pada layar LCD, kemudian membadingkan hasil pembacaan jarak pada sensor dengan pengukuran secara manual yang dilakukan menggunakan penggaris. Pada pengujian tersebut dilakukan percobaan sebanyak $6 \mathrm{kali}$, yang mana data hasil pembacaan sensor yang tertampil pada LCD dan data hasil pengukuran secara manual menggunakan penggaris, ditampilkan pada Tabel 1.

Tabel 1. Hasil Pengujian Sensor Ultrasonik HC-SR04

\begin{tabular}{|c|c|c|c|}
\hline No & $\begin{array}{c}\text { Data ketinggian dari } \\
\text { Sensor }(\mathrm{A})(\mathrm{cm})\end{array}$ & $\begin{array}{c}\text { Data ketinggian dari } \\
\text { Penggaris }(\mathrm{B})(\mathrm{cm})\end{array}$ & Selisih $(\mathrm{C})(\mathrm{cm})$ \\
\hline 1 & 5 & 5 & 0 \\
\hline 2 & 10 & 10 & 0 \\
\hline 3 & 15 & 15 & 0 \\
\hline 4 & 20 & 20 & 0 \\
\hline 5 & 25 & 25 & 0 \\
\hline 6 & 30 & 30 & 0 \\
\hline
\end{tabular}

Untuk variabel A adalah pengukuran jarak menggunakan sensor, sedangkan variabel B pengukuran jarak secara manual menggunakan penggaris dan untuk variabel $\mathrm{C}$ hasil selisih antara pembacaan pada sensor (A) dan pengukuran jarak secara manual (B). Berdasarkan Tabel 1, terlihat bahwa hasil pengukuran menggunakan sensor dan penggaris tidak terdapat selisih yang signifikan sehingga sensor bekerja dengan baik.

\subsection{Pengujian SIM800L}

Pengujian keberhasilan pengiriman pesan pada modul SIM800L dilakukan dengan membuat program pada mikrokontroler Arduino Uno berupa perintah mengirim pesan dari Arduino Uno ketika sensor mendapati jarak benda yang telah ditentukan. Tabel 2 menunjukan hasil pengujian keberhasilan pengiriman pesan pada SIM800L

Tabel 2. Hasil Pengujian Keberhasilan Pengiriman Pesan Pada SIM800L

\begin{tabular}{|c|c|c|}
\hline No & Keberhasilan SMS & Durasi Waktu (detik) \\
\hline 1 & Berhasil & 8 \\
\hline 2 & Berhasil & 7 \\
\hline 3 & Berhasil & 8 \\
\hline 4 & Berhasil & 7 \\
\hline 5 & Berhasil & 8 \\
\hline 6 & Berhasil & 8 \\
\hline
\end{tabular}

Berdasarkan tabel 2 di atas dapat diketahui bahwa modul SIM800L telah berhasil dalam mengirimkan pesan, untuk durasi waktu yang cukup stabil. Dengan demikian SIM800L dinyatakan dapat mengirimkan pesan rata-rata durasi waktu proses pengiriman pesan otomatis ketika mendapatkan sinyal dari Arduino Uno hingga pesan terkirim sebesar 7,6 detik.

\subsection{Pengujian Level Ketinggian BBM}

Pengujian level ketinggian BBM ini dilakukan dengan menggunakan pengukuran tandon BBM yang telah diberi tanda volume, yang dapat dibaca oleh sensor pada tiap-tiap volumenya. Pengukuran pada tandon dapat dilihat pada Gambar 3. 


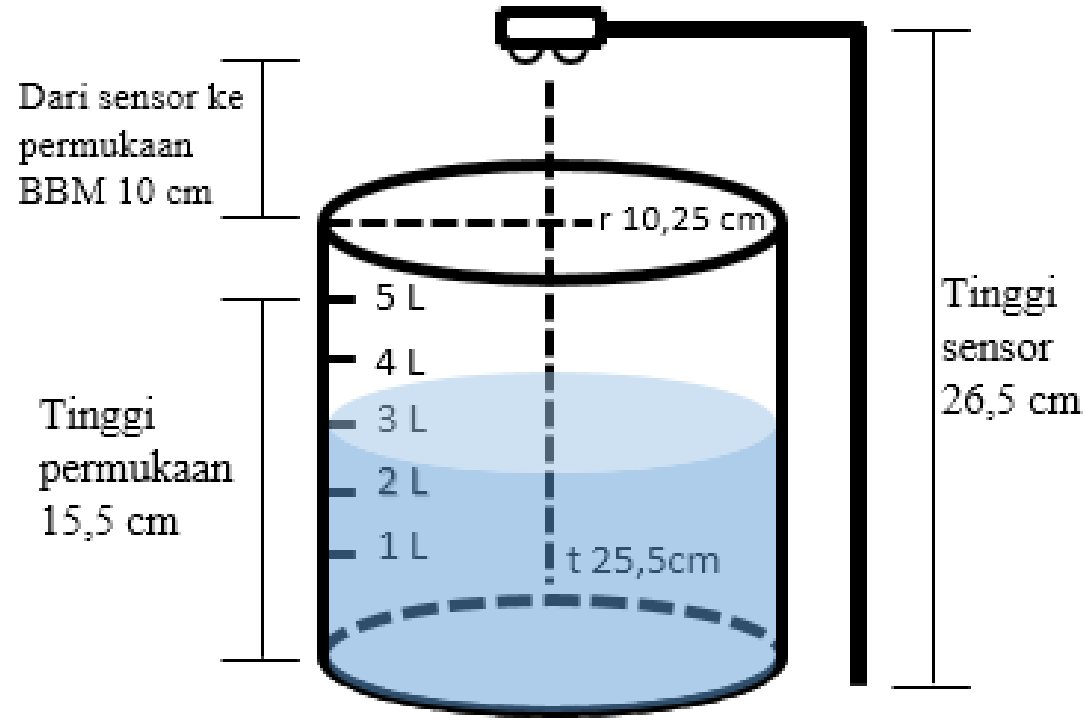

Gambar 3. Pengukuran Tandon

Tandon yang digunakkan berdiameter $10,25 \mathrm{~cm}$ tinggi permukaan $15,5 \mathrm{~cm}$ tinggi sensor $26,5 \mathrm{~cm}$ dan jarak sensor terhadap permukaan BBM 10cm. Berikut gambar proses pengujian level ketinggian BBM Gambar 3.

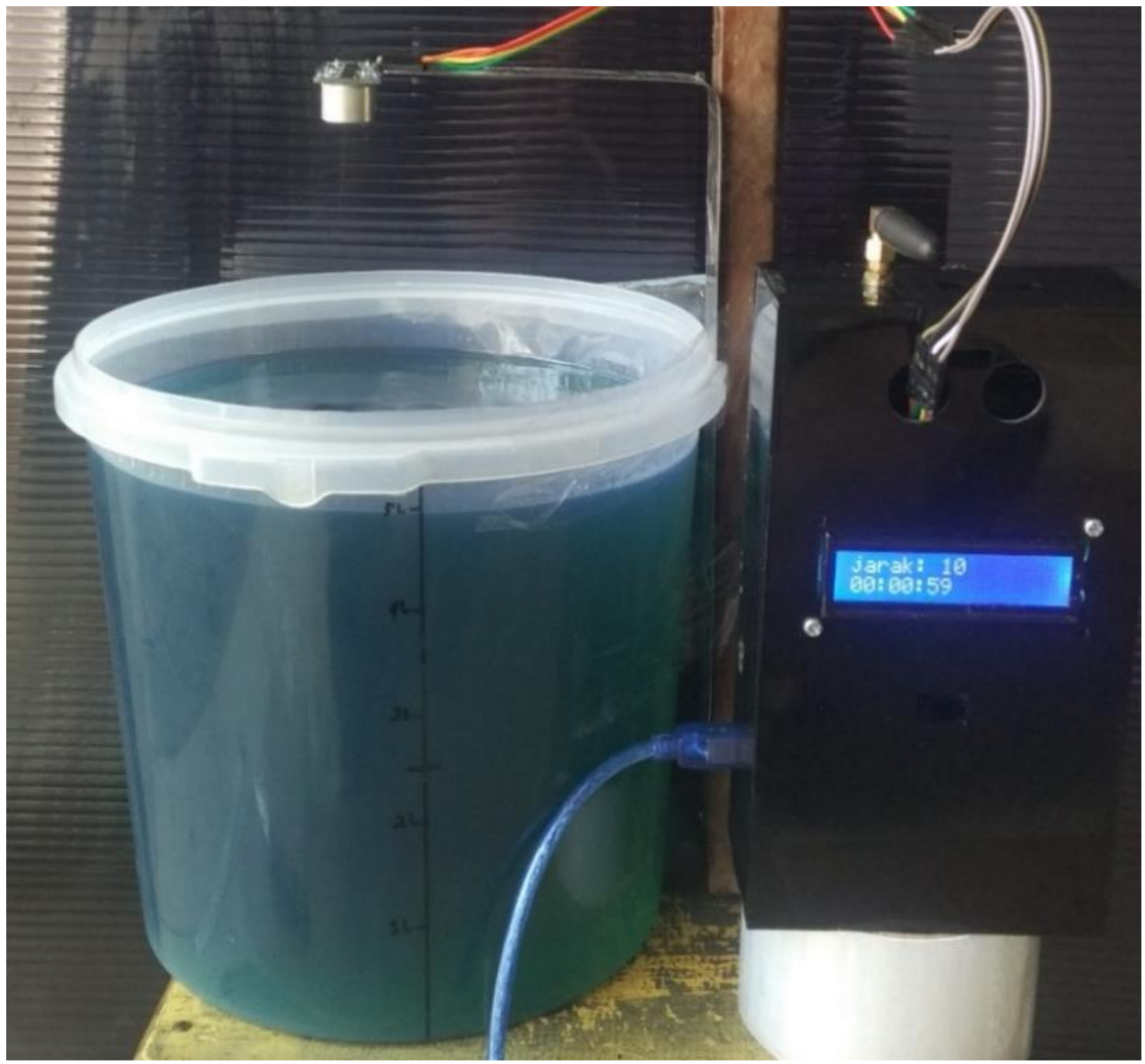

Gambar 4. Proses Pengukuran Level Ketinggian BBM

Berdasarkan proses pengukuran level ketinggian BBM tersebut maka didapatkan hasil dari pengujian level ketinggian BBM seperti terlihat pada Tabel 3. 
Tabel 3. Hasil Pengujian Level Ketinggian BBM

\begin{tabular}{|c|c|c|c|c|}
\hline No & Volume BBM (ml) & Sensor $(\mathbf{A})(\mathbf{c m})$ & Penggaris $(\mathbf{B}) \mathbf{( c m})$ & \% Selisih $(\mathbf{C})$ \\
\hline 1 & 5000 & 10 & 10 & $0 \%$ \\
\hline 2 & 4000 & 13 & 13,6 & $4,4 \%$ \\
\hline 3 & 3000 & 16 & 16,6 & $3,6 \%$ \\
\hline 4 & 2500 & 17 & 17,8 & $4,4 \%$ \\
\hline 5 & 2000 & 19 & 19,7 & $3,5 \%$ \\
\hline 6 & 1000 & 22 & 22,5 & $2,2 \%$ \\
\hline
\end{tabular}

Keterangan pada tabel 3: Volume BBM adalah nilai volume yang ada pada tandon BBM, variabel A adalah pengukuran jarak menggunakan sensor, sedangkan variabel B pengukuran jarak secara manual menggunakan penggaris dan $\mathrm{C}$ hasil nilai selisih antara pembacaan pada sensor dan pengukuran jarak secara manual. Untuk menghitung selisih antara variabel A dan variabel B dapat dihitung sebagai berikut:

$$
\frac{|a-b|}{b} \times 100 \%
$$

Berikut gambar grafik hasil dari tiap-tiap pengujian yang ditunjukkan pada Gambar 5.

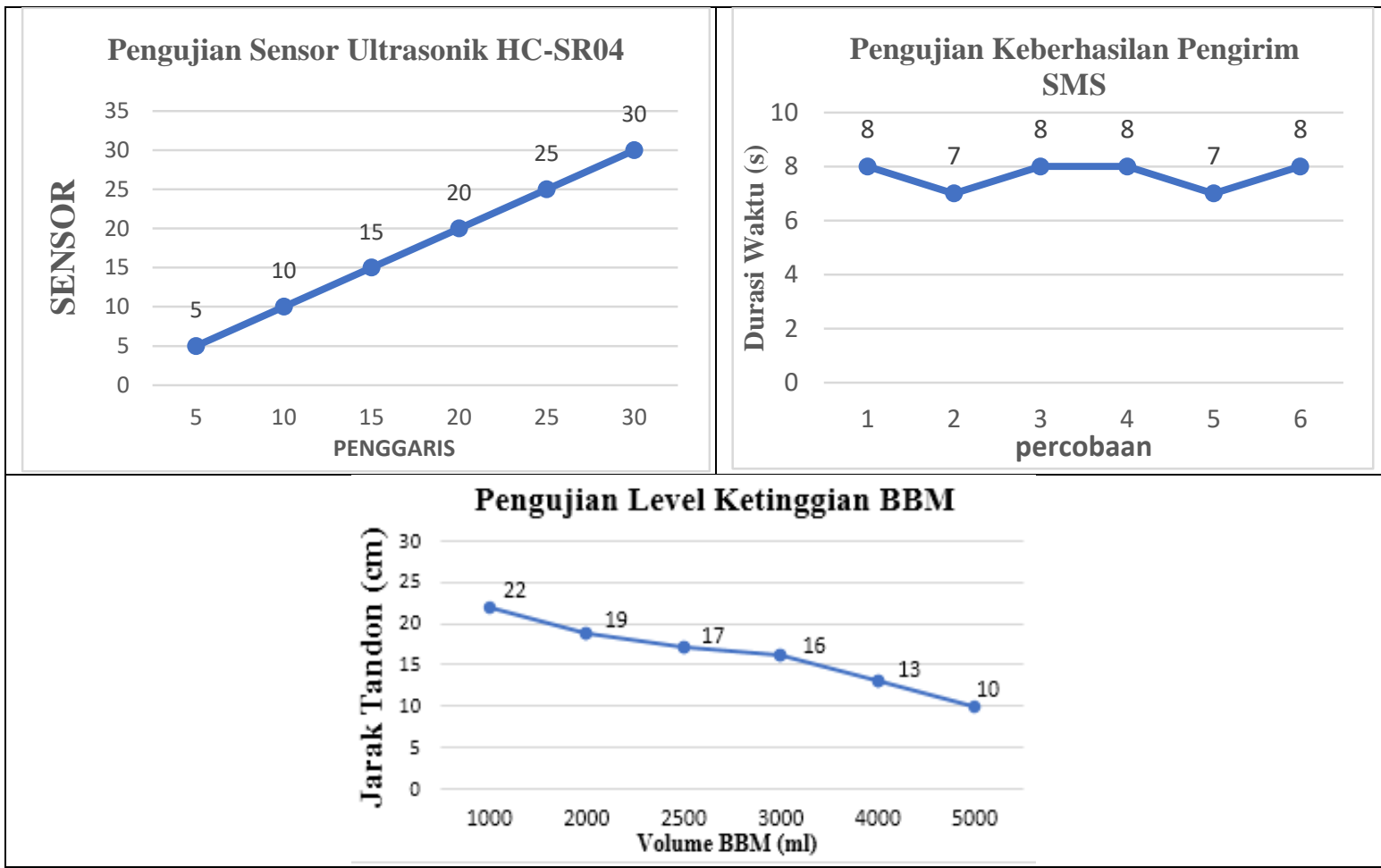

Gambar 5. Hasil Pengujian Sensor Ultrasonik, Pengiriman SMS, dan Level Ketinggian BBM

Berdasarkan hasil dari masing-masing pengujian pada Gambar 5, sensor ultrasonik HC-SR04 telah dapat membaca jarak tiap-tiap volume BBM pada tandon dengan tepat. Hasil pengujian keberhasilan SMS dalam mengirimkan pesan menunjukkan pesan telah dapat dikirim secara otomatis. Hasil pengujian jarak menunjukkan bahwa sistem telah dapat menampilkan kondisi volume tandon BBM sesuai dengan kriteria yang ditentukan yakni full on tank, medium on tank dan limit on tank.

\section{KESIMPULAN}

Berdasarkan hasil penelitian dan pembahasan yang telah dilakukan, dapat disimpulkan bahwa sistem yang dikembangkan yakni sistem telemetri pemantauan level ketinggian BBM berbasis SMS Gateway, telah 
berfungsi dengan baik. Sistem telah dapat mengirim secara otomatis informasi tentang limit on tank ke handphone penerima, dalam waktu yang relatif singkat yakni selama 7,6 detik.

\section{UCAPAN TERIMA KASIH}

Ucapan terima kasih disampaikan kepada editor dan reviewer atas segala saran, masukan dan telah membantu dalam proses penerbitan naskah. Ucapan terima kasih juga ditujukkan kepada pihak-pihak yang telah mendukung penelitian dan memberikan bantuan moral dan material, khususnya pihak SPBU UAD.

\section{REFERENSI}

[1] D. Setyoko, Tabah Priangkoso, "Analisis Konsumsi Bahan Bakar Sepeda Motor dengan Bahan Bakar Pertamax dan Pertamax Plus Menggunakan Dinamometer Chasis,” J. Ilm. Cendekia Eksakta, pp. 48-54, 2016.

[2] M. S. Tambun, N. Sudjarwanto, A. Trisanto, and A. L. Belakang, "Rancang Bangun Model Monitoring Underground Tank SPBU Menggunakan Gelombang Ultrasonik Berbasis Mikrokontroler,” Electr. - J. Rekayasa dan Teknol. Elektro, vol. 9, p. 2, 2015.

[3] D. D. Rizky Mahardhika, "Sistem Monitoring Level Tangki SPBU dan Mengukur Kadar Air Dalam Tangki," Simp. Nas. Teknol. Terap., pp. 65-70, 2013.

[4] H. S. Sendi, "Rancang Bangun Sistem Monitoring Jumlah Sisa Volume Minyak Underground Tank Berbasis Mikrokontroler," J. Teknol., vol. MI, 2018.

[5] C. V. Angkoso, W. Wahedah, and K. Joni, "Monitoring Stasiun Pengisian Bahan Bakar Umum Berbasis Augmented-Reality,” J. Ilm. Rekayasa, vol. 9, no. 2, p. 99, 2016.

[6] R. R. A. Siregar and R. Raymond, "Model Sistem Monitoring Tanki Bahan Bakar Minyak SPBU dengan Menggunakan Web Aplikasi dan SMS Gateway," JETri, vol. 12, 2015.

[7] Y. Kurniawan, "Implementasi Ultrasonik Level Detektor Pada Sistem Monitoring Tangki Pendam Pada SPBU," in Proceeding Seminar Tugas Akhir Jurusan Teknik Elektro, vol. 344, pp. 1-6.

[8] H. L. Sunardi, Hari Murti, “Aplikasi SMS Gateway,” J. Teknol. Inf. Din., vol. XIV, no. 1, pp. 30-34, 2009.

[9] Yusman, “Telemetri Pemantauan Ketinggian Air Sungai Melalui Komputer Teroptimasi Data Base Berbasis SMS," J. Teknol., vol. 13, pp. 25-28, 2013.

[10] D. P. Mangaraja et al., "Implementasi Sistem Pengukuran Otomatis Bahan Bakar di Tangki Genset dengan Sistem Monitoring Berbasis Jaringan,” in e-Proceeding of Applied Science, 2015, vol. 1, no. 3, pp. 2587-2594.

\section{BIOGRAFI PENULIS}

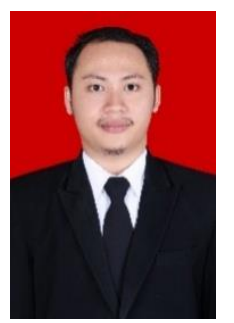

Yuda Indra Pranata adalah mahasiswa Program Studi S1 Teknik Elektro Universitas Ahmad Dahlan angkatan 2013 dan telah menyelesaikan pendidikan tersebut pada tahun 2019. Bidang peminatannya adalah otomasi industri.

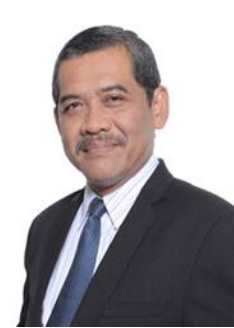

Dr. Muchlas M.T. adalah dosen Program Studi Teknik Elektro Universitas Ahmad Dahlan. Beliau menyelesaikan S1 Pendidikan Fisika di IKIP Yogyakarta pada tahun 1986, S2 Teknik Elektro di Universitas Gadjah Mada pada tahun 1998 dan S3 Pendidikan Teknologi dan Kejuruan di Universitas Negeri Yogyakarta 2013. 